\title{
LITERATURE
}

$\infty$

\author{
Michael Hall \\ Arizona State University \\ MJHALL9@ASU.EDU \\ HTTPS://ORCID.ORG/OOOO-0OO2-2957-6324
}

\section{Bibliotherapy and OCD: The Case of Turtles All The Way Down by John Green (2017)}

\begin{abstract}
This case study uses three different frameworks of inquiry to examine Turtles All the Way Down by John Green (2017) with a disability lens. The analysis extends beyond the traditional medical/ social dichotomy and considers how disability is tied to both agency and identity. Narratives and counter-narratives of disability are also investigated, as well as disability markers used in previous scholarship. The discussion concludes with an argument to include the novel in secondary English classes to create mental health allies. A consideration for medical humanities scholars is also included to use Green's text with patients with OCD, as a way for readers to find an identifiable protagonist.
\end{abstract}

Keywords: young adult literature; mental illness; obsessive-compulsive disorder (OCD)

\section{Introduction}

Adults with psychogenic disorders commonly use nonfiction texts and memoirs to understand themselves and seek relief; this is often known as bibliotherapy. For the teen reader, young adult fiction could play the same role. It is a more popular genre and could be used effectively in narrative medicine. In young adult literature, the adolescent reader is introduced to fictional characters that they can identify with, in a text that is accessible to their readiness as a developing reader. A subgenre of young adult literature, sometimes called "sick-lit," is becoming increasingly popular with readers of all ability levels and ages. This case study examines John Green's 2017 novel, Tur- 
tles All the Way Down, through a disability lens constructed of research questions used in previous case studies of different disability novels. John Green's portrayal of Obsessive Compulsive Disorder (OCD) in Turtles All the Way Down is authentic because it is informed by his own personal experience. This realistic portrayal enables the novel to be effectively used as bibliotherapy for readers with OCD, as well as to inform readers without OCD about the disorder. The societal implications of this increased understanding could potentially lower stigma.

\section{Expanding Beyond the Medical/Social Dichotomy of Disability}

The analysis of texts for authenticity must expand beyond the medical versus social discourse that is prevalent in disability studies. A medical lens, used by mental health professionals and the medical humanities community, refers to the scientific approach to mental illness and disability. Conversely, the social lens of disability views disability as not only a construct, but a universal experience. Even though this medical/ social binary of disability is at the root of disability studies discourse, a paradigm shift exposes different models of disability. Medical constructions of disability have been discarded in the past, in order to discuss disability as a social construct. Some authors, like Tobin Siebers (2011) and Kia Richmond (2014) approach disability discourse from both frameworks. While much of the disability discourse has centered around the medical/social dichotomy, recent scholarship has presented additional models of disability (Hughes 2017). In order to critically analyze young adult fiction for both authentic portrayals of mental illness and the social injustices of misunderstanding and stigma, a text must consider the medical, social, and expanded models of disability.

Research has already been completed in connecting medical definitions of psychogenic disorders and young adult literature. For the purposes of this study, psychogenic disorder refers to a disability that is mental, including but not limited to Obsessive Compulsive Disorder. In Mental Illness in Young Adult Literature: Exploring Real Struggles through Fictional Characters, Kia Richmond (2019) provides scientific definitions of different mental disorders, as well as discussing young adult literature that includes characters with disabilities. The definitions Richmond uses are taken from the Diagnostic and Statistical Manual of Mental Disorders, $5^{\text {th }}$ edition, frequently referred to as the $D S M-5$. Medical professionals consult this source when diagnosing and treating patients with psychogenic disorders. Richmond's book is a valuable source for future researchers to select disability texts from. In chapter six, Obsessive Compulsive Disorder is defined and Turtles All the Way Down is given a brief synopsis. Richmond discusses the diagnosis and symptoms of OCD (107), Green's portrayal of Aza's psychiatric treatment (109), and reactions from other characters who do not have the disorder (110). This case study considers Richmond's analysis while also approaching the portrayal of disability through other models of disability besides the medical and social. 
While much of the disability studies discourse has focused on the medical and social dichotomy, recent scholarship has provided additional models. Chloe Hughes (2017) provides five models of disability in "The 'Words Inside': Disabled Voices in Contemporary Literature for Young People" (187-203). Hughes includes 3 models beyond the medical and social: affirmation, generative, and charitable (189). While on the surface these three additional models are loosely related to social constructs of disability, Hughes defines the social model as viewing problems in the environment and "disabling societal barriers" (189). In the charitable model, Hughes defines disability as a negative trait, with characters with disabilities relying on the generosity of the able-bodied in order to function in society. This contrasts with Tobin Sieber's (2011) argument in Disability Theory that disability is never negative. Hughes's affirmative and generative models view disability in more positive ways. In the affirmative, disability is presented as "a positive identity for the individual or the group" (200). The generative model of disability expands beyond the affirmative, viewing disability as a trait that strengthens diversity, innovation, and resourcefulness (200). With these additional models of disability in place, Turtles All the Way Down can be analyzed through a disability framework that expands beyond the traditional medical vs. social conversation.

\section{Young Adult Literature and Psychogenic Disorders}

Young adult literature is a powerful tool for teenagers to discuss disability. Kurtts and Gavigan (2008) argue that bibliotherapy can be used to address "the needs of students with disabilities" as well as help "those without disabilities to understand the lives of children with special needs" (23). Any novels featuring disability should contain realistic portrayals of disability if they are going to be used for these two purposes, to help readers with and without disabilities. Without authentic or realistic portrayals, readers with psychogenic disorders could be persuaded to forgo medical care and able-bodied readers could potentially continue to perpetuate stereotypes and stigma.

Viewing disability in a positive view is not a new idea in disability discourse. Regardless, there still exists a societal stigma around discussing mental health and mental illness. Until relatively recently, disability studies focused primarily on physical disabilities. In 2014, the Language Arts Journal of Michigan devoted an entire issue to discussing mental illness and literature. In the issue, multiple articles are dedicated to using young adult literature to decrease stigma (Sirois 2014; Richmond 2014). With the increase in young adult literature featuring mental illness, it is appropriate to consider the societal implications of misrepresenting disability with false or negative portrayals. Texts that feature disabilities are so popular, some authors and critics refer to them as "sick lit." While it is important to include disability in young adult fiction, there should be a paradigm shift in the name of this subgenre. To continue to compare these texts as "sick lit" only adds to the stigma that psychogenic disorders are a negative or unhealthy quality. 
The inclusion of young adult literature that features disabilities in secondary classrooms is not a fad, trend, or something that will go away soon. Some researchers, such as Kurtts and Gavigan (2008), have studied how to educate pre-service teachers on creating thematic units that feature disability. Others have examined how issues of disability manifest in children's literature discussions (Adomat 2014). Curwood (2012), Monaghan (2016), and Wickham (2018) have each selected young adult texts and examined the constructions of disability. In "Redefining Normal," Curwood (2012) argues that disability texts can be critically analyzed through classroom discussion, thereby including social justice into the secondary English curriculum. The author concludes that this inclusion allows students to "gain insight into how authors craft normalcy narratives and disability counternarratives" (25). Monaghan (2016) provides "a set of criteria that serve as markers of YA texts that productively convey mental health experiences" (32). The productive nature of mental health portrayal is further examined by Wickham (2018) in "It's All in Your Head." In the article, Wickham warns of the dangers of misrepresentation and singular audiences. Wickham says, "If these novels are written exclusively for mentally ill adolescents to read, perhaps they will be perceived as inauthentically voiced. If, on the other hand, they are for a broader population, the character's voices might engender understanding regardless of authorial authenticity" (15). While the broader population might be learning and increasing their understanding, false portrayals can lead to increased stereotypes and decrease the chances that readers with psychogenic disorders will seek or continue to receive professional help. If young adult readers are going to be exposed to texts that include disabilities, it is important that authors provide authentic and realistic experiences.

\section{Creating a Disability Lens Using Previously Used Research Questions}

In addition to Hughes's models of disability, two authors provide disability markers or research questions that this case study drew from. Monaghan's disability markers were considered when examining Turtles All the Way Down's portrayal of disability and Curwood's research questions were used when investigating Green's normalcy and counter-normalcy narratives in the novel.

In "Evaluating Representations of Mental Health in Young Adult Fiction," Monaghan (2014) presents four markers for a text to be productive:

1. The protagonist/narrator accurately reflects the knowledge of someone his age under the circumstances in which he finds himself.

2. The protagonist's/narrator's illness experiences allow the reader to draw parallels between her life and experiences and those represented in the narrative.

3. The protagonist's/narrator's story rings true: if Point A is connected to Point B, it does so according to the logic of the narrative.

4. Somewhere in the narrative, the illness or condition is explicitly articulated (39). 
Jen Curwood (2012) defines normalcy and counter-normalcy narratives in "Redefining Normal: A Critical Analysis of (Dis)Ability in Young Adult Literature" (15-28). The article defines normalcy narratives as "restrictive or oppressive representations of disability." This is contrasted with disability counternarratives, which "question dominant assumptions about what it means to be able-bodied"(Curwood 2012, 21). These dual narratives should be considered when deconstructing any novel that features disabilities. Curwood (2012) used the following questions in her case study:

1 . Which character embodies or expresses a normalcy narrative?

2. Which character challenges a normalcy narrative? What are the personal or political implications of this challenge?

3. (How) does the author integrate a disability counternarrative into the storyline? (Thoughts, words, actions)

4. How does disability shape the character's identity? What other factors come into play as the character makes (and remakes) his or her identity?

5. How does the character's disability impact the way other characters perceive or respond to him or her?

6. Who has power? How does that change as the plot develops?

7. How does the setting of the novel influence character's identities?

8. For a character with a disability, where are the moments for agency within the story? (21).

\section{Methods}

Turtles All the Way Down (Green 2017) was selected for three reasons: 1) the novel contains a psychogenic illness, 2) the novel was published in the last 5 years, 3) the popularity of the author, John Green. The most recent of his novels, Turtles All the Way Down is already being adapted to film, expanding the story's audience. Green is no stranger to writing about disability; in his second most recent novel, The Fault in Our Stars, the two main characters both live with cancer. Richmond's book (date) cites the novel in its chapter on OCD and there is a need to continue to include mental health discourse in disabilities studies scholarship.

This case study aligns with previous articles that have evaluated novels featuring disabilities for authenticity and ability to decrease stigma. The research questions and disability markers listed in the previous section were used in the analysis of the text. There were three readings in this case study. In the first reading, the author developed a broad understanding of how disability is portrayed by John Green. In the second reading, Monaghan's disability markers were used to critically analyze the text to determine the productivity of the novel as an accurate representation of OCD. In the third reading, Curwood's (2012) research questions were used to find specific textual evidence to support the claim that Turtles All the Way Down could be used effectively in bibliotherapy. 


\section{Findings and Discussion}

Turtles All the Way Down by John Green is a young adult novel about two adolescent girls, Aza and Daisy, who are searching for the body of Mr. Pickett, a billionaire who disappeared the night before being arrested. The story is told from the point of view of Aza. The two girls are initially motivated by the $\$ 100,000$ reward for information leading to the arrest of Mr. Pickett. Aza, who went to a trauma camp with Davis Pickett, the elder Pickett's son, is given $\$ 100,000$ by Davis to stop searching. Over the course of a few months, Aza and Davis begin dating casually. The novel ends with an anonymous tip to the police hotline that solves the disappearance. Davis and his younger brother, Noah, move to Colorado and it is unclear whether they keep in contact with Aza. This external conflict is juxtaposed with Aza's inner struggle with Obsessive-Compulsive Disorder. Aza's mental illness not only affects her relationship with Davis, but also her friendship with Daisy and her family relationship with her mother, Ms. Holmes. When the text is analyzed with Hughes's five models of disability, Monaghan's four disability markers, and Curwood's normalcy/counter-normalcy narrative inquiry questions, it becomes apparent that the novel could be productively used in narrative medicine with readers with OCD, as well as in literature discussions with readers without the disorder. In the first group, readers with OCD are presented with a protagonist that they can identify with and learn from. In the second group, readers without OCD are presented with an opportunity to learn about one person's struggle with the disorder, potentially raising understanding, creating a mental health ally, and decreasing stigma surrounding psychogenic disorders.

\section{Authenticity of the Portrayal of Mental Illness}

Aza's inner monologue and description with of her ritual is an accurate and authentic portrayal of Obsessive-Compulsive Disorder. In Mental Illness in Young Adult Literature, Kia Richmond (2019) presents the DSM-5 definition of OCD: "the presence of obsessions (described as reoccurring and persisting thoughts, impulses, or images that one experiences as invasive or unwanted) and/or compulsions (behaviors or mental acts that one feels obliged to do in response to an obsession or a set of rules that must strictly be followed)" (97). This medical definition of OCD aligns with Green's portrayal of Aza's intrusive thoughts, which she describes as "invasive" (46). Aza's intrusive thoughts are present throughout the entire novel. The protagonist does not find a cure and her struggle with the psychogenic disorder worsens before she finds relief. To compensate for the intrusive thoughts, Aza completes a frequent ritual: pressing her thumbnail into her middle finger until the callus she developed cracks open, washing and sanitizing the wound, and applying a fresh Band-Aid (5-6, 46-47, 69, 130, 133, 242). While Aza completes the action, the ritual seems beyond her control. Even when she is presented with the $\$ 100,000$ that she splits with Daisy, Aza is late to a bank appointment because she compulsively pulls over and completes her ritual. Eventually, 
when making her finger bleed and bandaging it is no longer enough, Aza upgrades to drinking hand sanitizer $(210,229)$. In her mental health appointments with Dr. Singh, Aza complains that she does not feel in control of her thoughts or actions. Aza quietly says to herself, "I think, You will never be free from this. I think, You don't pick your thoughts. I think, You are dying, and there are bugs inside of you that will eat through your skin. I think and I think and I think" (92). A theme of feeling out of control is present throughout the entire novel.

Not only is Aza's disorder accurately represented, but her mental health treatment is also authentically portrayed. The novel makes an explicit mention of the cognitive behavioral therapy that Aza undergoes. Regular visits with Dr. Singh are not new to Aza, nor does she overcome her illness to no longer need them. Instead, Aza's therapy is reactive to her struggle. Before the events of the novel, Aza's visits with Dr. Singh were eight weeks apart. This changes once Aza's intrusive thoughts become more prevalent. Green writes, "She told me she wanted to see me in ten days. You can kind of measure how crazy you are based on how soon they want to see you back. Last year, for a while, I'd been at eight weeks. Now, less than two" (91). When Aza is hospitalized with a lacerated liver and is caught drinking hand sanitizer, these appointments with Dr. Singh occur daily (233). Dr. Singh is portrayed as a competent, caring psychiatrist that is familiar with Aza's intrusive thoughts and compulsions. The psychiatrist is cognizant of the fact that Aza does not take her medication daily (88), something that is not uncommon to mental health patients. Narrative medicine is also portrayed when Dr. Singh and Aza read a passage from Ulysses during a routine visit (166). Aza struggles with, but does not overcome, her chronic illness and her journey is authentically represented through her treatment, medication, and the impact of her disorder on her relationships with others.

\section{The Social Effect of OCD on the Protagonist}

The social model of disability is represented through Aza's relationships with her mom, Daisy, and Davis. In all three relationships, Aza's mental health journey presents conflict. Ms. Holmes struggles to understand her daughter's illness, often asking questions that exacerbate Aza's anxiety. Daisy, Aza's best friend since the two were six years old, frequently supports Aza despite Aza's failure to reciprocate support when Daisy needs it. Davis and Aza's relationship is strained after the two kiss and Aza's invasive thoughts convince her that Davis's microbiota would infect her, eventually causing her to swallow hand sanitizer.

Early in the novel, Ms. Holmes asks Aza if she is feeling anxious, as well if she is taking her medication as prescribed (11). Later, when Aza expresses her doubt about the medication, Ms. Holmes asks her to "be honest" with Dr. Singh in order to decrease her suffering (70). As Aza's anxiety worsens, Ms. Holmes takes notice, saying, "I don't know what to say, Aza. I see the pain on your face and I want to take it from you" (135). Aza recognizes her disorder's impact on her mother and confesses to the 
reader, "I hated hurting her. I hated making her feel helpless. I hated it" (135). The mother-daughter conflict also extends beyond Aza's disability; the relationship has been strained with Mr. Holmes's unexpected death years prior, as well as Aza's upcoming senior year and the college applications that the family cannot afford. However, by the end of the novel, Ms. Holmes's attempt to relate to her daughter is still strained. The constant questions are answered with, "Is there any way we can make a deal where I tell you when I have a mental health concern instead of you asking?" (272). Since Aza's relationship with OCD is a lifelong journey, it's appropriate that Ms. Holmes would continue to take a motherly approach as she continues to attempt to support her daughter. While this support is often smothering, it is well-intentioned. Any parent that is struggling to understand their child's mental illness could read and learn from Aza and Ms. Holmes's relationship.

Daisy and Aza's relationship is a complex one that is founded in support, but often provides conflict. Best friends since the age of six, Daisy's friendship with Aza transcends the class differences between the two, as well as their psychogenic differences. Whereas Daisy is confident and independent, Aza often feels like she is not in control. When Aza introduces Daisy to the reader, Aza describes herself as "the Sidekick" (2). Aza relies on Daisy's friendship, even if she is unsure why Daisy continues to be her friend. Aza laments, "Sometimes I wondered why she liked me, or at least tolerated me. Why any of them did. Even I found myself annoying" (7). Daisy also recognizes Aza's thought spirals and provides support, often talking her through them. Some of Daisy's conversations with Aza are more productive than therapy appointments with Dr. Singh. Aza narrates, "So often, nothing could deliver me from fear, but then sometimes, just listening to Daisy did the trick. She'd straightened something inside me, and I no longer felt like I was in a whirlpool or walking an ever-tightening spiral" (66).

Despite this support, Aza's illness eventually takes a toll on Daisy. In her fan-fiction blog which Daisy creates throughout the course of the novel, Daisy created a character named Ayala. Not only are Aza and Ayala's names similar, but the two were also both filled with anxiety. Ayala is presented as a foil, often presenting situations that the main characters must save her from. One story even refers to Ayala as a "burden" (198). When Aza discovers Daisy's blog, she quickly makes the connection between herself and Ayala. This causes Aza to experience painful thought spirals over a few days. On one hand, Aza agrees with Daisy's portrayal, regardless of how painfully similar it is. Conversely, Aza feels betrayed that her best friend would write about her in that way in a public forum: the internet. Unfortunately, Aza waits to confront Daisy until the two are driving. Distracted, Aza has an anxiety attack and rear ends a vehicle, causing a car accident (214-17). After Aza spends time in the hospital for her lacerated liver and receives inpatient treatment for her OCD, the two mend their friendship (245). By the end of the novel, Aza and Daisy even create a Mental Health Alliance at their school (281). Daisy and Aza's relationship could be used by secondary students to analyze the complexities of being a mental health ally. Daisy is fictional evidence of one way to support a friend with OCD, as well as the dangers of misrepresentation. 
Davis and Aza are first introduced before the novel's opening when the two characters attend a camp for kids that have experienced the death of a parent. This connection is exploited by Daisy after the disappearance of Davis's father, Mr. Pickett, and the reward announced on the radio for information leading to his capture. After Davis learns that Aza and Daisy are looking for his father for the money, Davis gives Aza \$100,000 in cash, the same amount of the reward. The gift from Davis comes with one condition: that Aza and Daisy stop searching for Mr. Pickett. Whereas Daisy is appeased with the money, Aza cannot stop thinking about Mr. Pickett. As Aza grows closer to Davis, the two eventually date. Aza often worries about Davis and his brother, Noah. After Aza and Davis kiss, Aza begins experiencing thought spirals about the germs that the two exchanged orally. This eventually manifests with Aza adding swallowing sanitizer to her daily ritual. Despite Daisy's ability to understand and accept Aza's OCD, Aza does not extend the same opportunity to Davis. Once Aza leaves the hospital, she breaks up with Davis. The two remain apart until Aza discovers the location of Mr. Pickett's body in Pogue's Run, an underground sewer. As Aza and Davis both heal from their break-up, Aza's visits with Dr. Singh become less frequent; from daily appointments to every eight weeks. Davis, the heir of a billionaire, and Aza, the daughter of a public-school teacher, are also separated by differences in class. While this class difference is not common, the relationship could be examined by readers curious about the implications of mental health and dating. Readers become aware of how Aza's disorder negatively affects Davis, as well as how Davis's attempts at a "normal" relationship cause Aza anxiety and thought spirals.

\section{Charitable, Affirmation, and Generative Models of Disability}

Charitable, affirmation, and generative models are also included in Turtles All the Way Down. The charitable model, the view of disability as a deficit, is highlighted in Aza's description of her battle with OCD. The cognitive behavioral therapy with Dr. Singh provides examples of affirmation models of disability, the positive portrayal that depicts OCD in a more positive view. Dr. Singh's use of narrative medicine, specifically the allusions to Ulysses and Edgar Allan Poe, aligns with the generative model, where disability is presented as an advantage.

With exception to Daisy's fan-fiction, it is Aza's depiction of her illness that most aligns with the charitable model of disability. Aza refers to herself as "crazy" more than once $(133,237)$. She refers to her illness as a burden on herself, her mother, her best friend, and her boyfriend. In response to Dr. Singh's insistence to view her disability in a positive manner, Aza thinks, "I guess she was trying to make me feel better, but I find mental disorders to be vastly overrated. Madness, in my admittedly limited experience, is accompanied by no superpowers; being mentally unwell doesn't make you loftily intelligent any more than having the flu does" (133). When Aza returns to school after being in the hospital for two weeks, she worries that everyone will think she's "crazy," a statement that Ms. Holmes agrees with in jest (237). By the end of the 
novel, Aza's view of her disorder eventually transforms to a more positive one. However, for the majority of the novel Aza presents her mental health journey as a negative, painful one.

Whereas the charitable model presents disability as a negative quality, the affirmation model takes an opposite approach, viewing the exceptionality as an asset. Aza describes being "worrisome" as the "correct worldview" (52). As Aza and Daisy reconcile their friendship, Daisy pleads for her friend to soften her self-critical approach. Daisy says, "What I want to say to you, Holmesy, is that yes, you are exhausting, and yes, being your friend is work. But you are also the most fascinating person I have ever known, and you are not like mustard. You are like pizza, which is the highest compliment I can pay a person" (238). Despite the challenges that Aza's OCD brings to her friendship with Daisy, the disorder is ultimately accepted and bridged.

The generative model of disability is the one least represented in the novel, however, there are two clear representations. The first involves bibliotherapy sessions with Dr. Singh where Ulysses and Edgar Allan Poe are discussed (132). The second instance is in the climax of the novel, when Aza and Daisy are travelling through the sewers underground. Daisy, surrounded by rats in the dark, is understandably upset and scared. Aza, however, feels in control for one of the first times in the novel. Her constant worries are finally transformed to a position of power. With the flashlight in her hand, Aza's thought spiral connects the foul smell to Mr. Pickett's note of "Pogues Run" (266). Aza's cognitive processes allowed her to solve a case before the police department.

\section{Disability Markers}

John Green's portrayal of Aza's fight with OCD aligns with Monaghan's four disability markers. Aza's narration accurately reflects one view of the adolescent experience and it is presented in a way that adolescent readers with OCD could identify with. The novel is not just about Aza's experience with OCD. Green also portrays the complexities of teenage friendships, romantic relationships, and conflict between parents and their children. Aza, Daisy, and Davis all live different experiences, presenting the reader with multiple windows into the teenage experience. With Aza, the reader is introduced to a character in a single-parent household during a transformative time. While Aza is only a junior in high school, her upcoming college applications provide stress between the mother and daughter. This authentic portrayal reflects an experience that some teenage readers could identify with. Daisy's relationship with Mychal is different than Aza and Davis's relationship. Daisy is confident in her desire to have a physical relationship with Mychal, often complaining to Aza that Mychal wants to take a slower approach. This take on a heterosexual relationship contrasts with generalized stereotypes of males pressuring females into sexual relationships. While Daisy comes from a lower-class background, Davis is the son of a billionaire. Daisy, Davis, and Aza are all accurate reflections of adolescent experiences that readers could identify with. 


\section{The Authority of the Author to Speak About OCD}

Green's portrayal of Aza's OCD is also presented in a way that readers with OCD could identify with. By presenting a medically authentic view of OCD, the novel presents an opportunity for readers with OCD to draw parallels between their lives and Aza's mental health journey. Aza's journey is a truthful one. Her disorder is never presented as one that can be cured, only treated. The treatment that Aza receives is aligned to her illness and adjusts when Aza loses control of her compulsions. Not only are the illness and rituals explicitly stated, but the treatment that Aza receives takes place across the entire novel. OCD is never presented by characters other than Aza as a burden, only one part of her complex identity. Aza narrates her journey with the reader early on, saying, "Admittedly, I have some anxiety problems, but I would argue it isn't irrational to be concerned about the fact that you are a skin-encased bacterial colony" (3). Later on, Aza describes her disorder in greater detail: "I have these thoughts that Dr. Karen Singh calls 'intrusives,' but the first time she said it, I heard 'invasives,' which I like better, because, like invasive weeds, these thoughts seem to arrive at my biosphere from some faraway land, and then they spread out of control" (45). This portrayal of OCD is informed from John Green's own lived experience. In the acknowledgements page of the novel, the author thanks two psychiatrists that have supported his own mental health journey. Because of this, Green can speak with authority and present a portrayal of mental illness that is authentic and identifiable for readers with OCD.

\section{Normalcy/Counter-normalcy Narratives}

Normalcy and counter-normalcy narratives are presented throughout the novel. As Aza struggles to understand and cope with OCD, she participates in a normalcy narrative. When asked how she is doing, Aza says, "I mean, I'm still crazy, if that's what you're asking. There has been no change on the being crazy front" (86). For Aza, OCD makes her abnormal and, in her opinion, her struggle lies in overcoming the disorder. In a thought spiral about Davis, Aza says, "I just wanted to be with him like a normal person would. I wanted to feel the brain-fuzzing intimacy I'd felt when texting with him, and I liked kissing him" (179). Aza's normalcy narratives are challenged in her visits with Dr. Singh. Not only does Dr. Singh advocate for Aza to practice self-care, but she also implores Aza to change her perspective on living with OCD. Dr. Singh says,

The term chronic pain captures nothing of the grinding, constant, ceaseless, inescapable hurt. And the term crazy arrives at us with none of the terror and worry you live with. Neither do either of those terms connote the courage people in such pains exemplify, which is why I'd ask you to frame your mental health around a word other than crazy" (89).

In more than one session, Dr. Singh reminds Aza that her struggle is not "uncommon" $(86,92,163)$. 
Dr. Singh's sessions with Aza also present a disability counter-narrative into the storyline. In one session, Dr. Singh says, "I've noticed you use that word a lot, crazy. And you sound angry when you say it, almost like you're calling yourself a name" (86). Aza's reluctance to be proactive in her mental health care is challenged on more than one occasion by Dr. Singh, who insists that Aza can live a productive life with OCD. While Aza initially resists the idea of going away to college - an idea supported by her mother - by the conclusion of the novel the reader is given a glimpse into Aza's future. What awaits her is a life that would be normal for someone with OCD: a continual struggle to live with the disorder. However, despite the lifelong challenge, Aza grows stronger with time. One of her last words to the reader are, "I, a singular proper noun, would go on, if always in a conditional tense" (285). Aza's struggle never goes away, however, she does learn coping skills to live a productive life.

\section{Mental Illness as an Identity Marker}

Obsessive Compulsive Disorder is unconsciously linked to Aza's identity. From the first page of the novel, Aza questions if she or her compulsions are in control. When considering if she was in fact fiction herself, Aza says, "Of course, you pretend to be the author. You have to" (p. 1). As the reader progresses through the novel, Aza's struggle with OCD continues to be tied to her identity. Not only does she feel like the sidekick to her best friend, but she feels like a passenger in her own body; a slave to her "intrusives" and compulsions. Aza's thought spirals dominate her attention and in her interactions with Daisy, Davis, and Ms. Holmes, she is frequently only there in person, distracted with thoughts elsewhere.

In addition to being linked to identity, Aza's OCD is connected to the power she does and does not possess. The reader is introduced to Aza, as she eats lunch in the cafeteria, a timeframe she does not have control over. She complains and then questions her mother on this lack of control, saying, "It's just weird, how this is decided by someone I don't know and then I have to live by it. Like, I live on someone else's schedule. And I've never met them" (11). This is immediately after Aza exits a thought spiral where she fears she has contracted c. diff from the lunch room (5). Aza is often powerless to her own thoughts and compulsions, as well as in her position as an $11^{\text {th }}$ grader in an American public high school. Aza's complaints of Ms. Holmes's "helicopter parenting" (115) display the power dynamic between the mother and daughter. At school, Aza is second to her friend Daisy, whom she frequently gives rides to. While they are equal as best friends, Daisy clearly does more of the talking.

Despite this power dynamic, there are moments of agency for Aza in her struggle with OCD. A frequent respite from her thought spirals are trips around Indianapolis in Harold, her car. Even though Aza ends up crashing Harold after an argument with Daisy, the fight is a culmination of Aza thinking about saying something and standing down. Finally, when Aza cannot take the thought spirals about her best friend any 
longer, she fatefully chooses to advocate for her feelings while driving. The result is a car accident and two-week trip to the hospital (233).

\section{Implications for future research}

According to the National Institute of Mental Health, 1.2\% of Americans live with Obsessive-Compulsive Disorder. This low frequency presents two negative opportunities: the lack of representation for those that live with the disorder and the misrepresentation of the disease and lack of understanding for those that may never see a real-life example. While OCD is not as prevalent as other psychogenic disorders, 1 in 5 people will seek some form of mental health treatment for it in their lifetime. Bibliotherapy/narrative medicine is a way for readers with disabilities to seek understanding, as well as for non-disabled readers to increase empathy. This creates a need for authentic portrayals of disabilities in fiction texts.

Future case studies could continue to analyze different novels that feature psychogenic disorders, curating research questions from past case studies. These questions of inquiry could be refined and replicated, eventually resulting in a disability lens that any researcher could use when approaching a text with a critical eye for authenticity in the representation of the portrayed disability.

This case study was a critical analysis of the text from a disability studies perspective. Future analyses could also approach the text from a feminist critique, examining the romantic relationships between the two couples: Daisy and Mychal and Aza and Davis. One could also approach the text from a trauma studies perspective to investigate how Aza and Ms. Holmes deal with the death of Mr. Holmes and how Davis and Noah react to their mother's death and father's disappearance. Furthermore, a youth lens (Petrone et al 2015) could be applied to analyze the portrayal of the adolescent experiences of the characters. Davis and Noah's billionaire status contrasted with Daisy's working-class background provides an opportunity to examine the non-universal adolescent experience that Green portrays.

\section{Conclusion}

Turtles All the Way Down should be considered as a productive text in narrative medicine discourse because of John Green's commitment to portraying an authentic and realistic experience with Obsessive Compulsive Disorder. The text could potentially be used in bibliotherapy to help an adolescent with OCD identify with a character with a similar worldview. Additionally, the text could also be used in secondary English classrooms to create mental health allies during literature discussions. The concept of including texts portraying characters with disabilities into the classroom is not new. Richmond (2014) introduced English teachers to approaches to expand the traditional canon in order to 
include culturally relevant literature (19). The novel's addition to the secondary English curriculum would be beneficial to all readers because the novel provides multiple opportunities to discuss disability and the societal implications of living with a disability.

This exposure to a character with a disability helps give those with OCD a voice, while also increasing understanding in readers without disabilities, potentially decreasing stigma. Because novels featuring characters with disabilities serve two purposes, it is essential that authors and critics consider the realism behind the portrayal. In this case study, three different frameworks of inquiry were used across three different readings. Hughes's five models of disability, Monaghan's disability markers, and Curwood's normalcy/counter-normalcy narratives are all present in the text. While additional studies could continue to investigate the text from a disability lens, the alignment with these three frameworks suggests that the novel is an authentic portrayal of OCD. This is confirmed with Green's admission of seeking mental health treatment himself. Turtles All the Way Down extends beyond entertainment: it persuades readers with OCD to keep fighting and it informs readers without the disorder about the challenges many face daily.

\section{References}

Adomat, Donna Sayers. 2014. "Exploring Issues of Disability in Children's Literature Discussions." Disability Studies Quarterly 34 (3): 1-17. https://doi.org/10.18061/dsq.v34i3.3865

Curwood, Jen Scott. 2012. "Redefining Normal: A Critical Analysis of (Dis)Ability in Young Adult Literature." Children's Literature in Education 44 (1): 15-28. https://doi.org/10.1007/ s10583-012-9177-0.

Green, John. 2017. Turtles All the Way Down. New York: Penguin Books.

Hughes, Chloe. 2017. “The 'Words inside': 'Disabled' Voices in Contemporary Literature for Young People.” Journal of Literary \& Cultural Disability Studies 11 (2): 187-203.

Kurtts, Stephanie A., and Karen W. Gavigan. 2017. "Understanding (Dis)Abilities through Children's Literature.” Education Libraries 31 (3): 23. https://doi.org/10.26443/el.v31i3.259.

Monaghan, Alison. 2016. "Evaluating Representations of Mental Health in Young Adult Fiction: The Case of Stephen Chbosky's The Perks of Being a Wallflower." Enthymema 16: 32-42.

Petrone, Robert, Sophia Tatiana Sarigianides, and Mark Lewis. 2015. "The Youth Lens: Analyzing Adolescence/ts in Literary Texts.” Journal of Literacy Research 46: 506-33.

Richmond, Kia Jane. 2014. "Using Literature to Confront the Stigma of Mental Illness, Teach Empathy, and Break Stereotypes.” Language Arts Journal of Michigan 30 (1). https://doi. org/10.9707/2168-149x.2038.

Richmond, Kia Jane. 2019. Mental Illness in Young Adult Literature: Exploring Real Struggles through Fictional Characters. Santa Barbara, CA: Libraries Unlimited, an imprint of ABCCLIO.

Siebers, Tobin. 2011. Disability Theory. Ann Arbor, MI: University of Michigan Press. 